\title{
O OLHO E O RETRATO: ASPECTOS METAFÓRICOS DA TEORIA DO FATO JURÍDICO
}

\author{
Torquato da Silva Castro Júnior \\ Faculdade de Direito do Recife, Universidade Federal de \\ Pernambuco - UFPE, Pernambuco. \\ torquatojr@yahoo.com
}

\begin{abstract}
RESUMO: Este trabalho pretende analisar - e na mesma medida elogiar - sob uma perspectiva retórica, a teoria do fato jurídico desenvolvida por Pontes de Miranda, com destaque para a ontologia de seu "mundo do direito", verificando assim sua importância para conferir uma caracterização de objetividade ao Direito, importante estratégia discursiva.
\end{abstract}

PAlAVRAS-CHAVE: Teoria do fato jurídico. Retórica. Pontes de Miranda.

The eye and the portrait: metaphorical aspects of the juridical fact theory

ABSTRACT: This paper intends to analyze - as well as compliment - under a rhetoric perspective, the juridical fact theory developed by Pontes de Miranda, focusing on the ontology of its "world of law", thus acknowledging its value in providing the Law with a characterization of objectivity, an important speech strategy.

KEYWORDS: Juridical fact theory. Rhetoric. Pontes de Miranda.

\section{A TRADiÇÃo CIVILÍSTICA E A TEORIA dO FATO JURÍDiCO}

A tradição jurídica a que se convencionou chamar "romanista" absorveu da Modernidade formas de pensar geometrizantes, sistêmico-dedutivas, vivenciadas como refinamento científico do saber jurídico. O Jusracionalismo, ou Direito Natural Racional, desenvolveu-as inicialmente e depois, por meio das grandes codificações jusnaturalistas e pelas mãos da pandectística oitocentista alemã, essas formas de pensamento alcançariam diretamente a práxis forense dos países dessa tradição (WIEACKER, 1957, p. 292-293). Em muitos aspectos, semelhantes formas de pensar, enfatizando a "sistematicidade do direito" e, às vezes também, a possibilidade de serem "calculadas" logicamente as decisões jurídicas, permanecem vigentes hoje, não apenas do outro lado do Atlântico, mas cá deste lado também.

A introdução do "pensamento sistêmico" (CANARIS, 1989), i.e. da forma cartesiana de pensar o jurídico, no direito civil brasileiro verificou-se principalmente pelo influxo das codificações européias e pelo influxo da pandectística. Nesta tradição civilista romanista, não é preciso dizer, situa-se a obra de juristas tais como Pontes de Miranda e Marcos Bernardes de Mello.

A presente intervenção pretende ter, afinal, natureza laudatória. O elogio será o do jurista inserido nesta respeitável tradição, por seu refinamento como cultor dessas categorias com que afinal se pensam o direito, mas também o elogio da teoria do fato jurídico, como tal, igualmente 
por seu refinamento como doutrina. Para essa tradição, o conceito próprio de "fato jurídico" figurará como o mais relevante, sob essa óptica, para a construção de uma "teoria" do direito. ${ }^{1}$

A teoria do fato jurídico, como desenvolvida por Pontes de Miranda e preservada em Alagoas com elegância coerência e originalidade pelo ora homenageado; como também a teoria do fato jurídico de Lourival Vilanova, retomada em São Paulo por Paulo de Barros Carvalho, encarnam exemplarmente o objeto do elogio (e da crítica) à dogmática jurídica em terras brasileiras. Ambas as teorias serviriam, de maneira diversa mas análoga, ao propósito da presente análise, em razão da maneira como concebem o direito, ou uma "parte" dele ao menos, como sendo "uma lógica". A presente exposição limitar-se-á, entretanto, à metafórica da obra mirandiana, que é também a metafórica do homenageado, por questões de espaço e oportunidade.

Vale explicitar desde já, entretanto: a abordagem da teoria do fato jurídico que aqui se desenvolve parte de uma perspectiva tomada desde a "retórica jurídica", cuja característica marcante traduz-se na minimização de "fantasias metodológicas" (GAST, 2006).A questão da lógica como teoria do direito, na obra de Pontes de Miranda, será observada desde um ponto de vista que lhe é exterior: desde a consideração do papel retórico da invocação "lógica" e da reconstrução do "sistema jurídico", do "mundo do direito", nas metáforas topológicas do referido autor. A abordagem retórica que se pretende desenvolver consiste em tomar o problema da ontologia do direito, do "mundo do direito" (como o chama Pontes de Miranda), deste "lugar" onde as coisas relativas à dinâmica do fato jurídico "situam-se" afinal, como uma metáfora espaço-temporal constitutiva mesmo das formas com que se instanciam os eventos que se pretende "descrever".

Não se trata aqui de discutir se "existe" ou não, com efeito, o "mundo do direito". Ninguém negará talvez que, como realidade, o direito é principalmente uma convenção. ${ }^{2}$ Ademais, uma questão desse tipo seria uma armadilha do sem-sentido.

As metáforas espaciais e visuais estão postas nos textos da teoria do fato jurídico de Pontes de Miranda. Só não são levadas a sério pela própria teoria, porque abertamente são metáforas. Para que fossem sérias, teriam de se travestir de literalidades. Seriam as metáforas, segundo a mentalidade tradicional, um expediente pedagógico, útil, mas dispensável em última instância. Tanto assim ocorre que, na doutrina de Vilanova, por exemplo, já aparece bem mais dissipado o uso aberto das metáforas. Ciência seria coisa da linguagem literal e por isso também se aproximaria das matemáticas, cuja univocidade, como a da lógica, não se pode questionar. Uma abordagem retórica permite inverter essa situação e tratar as metáforas como elementos centrais de indagação e a pretendida "matematização" como expediente de persuasão.

\section{O CÉU CONCEITUAL DOS JURISTAS}

Convém reconhecer, inicialmente, como Jhering (1974): muitas teorias da dogmática existem em instâncias tão etéreas que realmente não vêm a afetar a prática jurídica. Jhering falava do juristichen Begriffshimmel, do "céu" conceitual dos juristas.

Para exemplificar a alegada dissociação entre teoria e prática, tome-se já da civilística o problema do status do nascituro, na teorização pela doutrina do conteúdo do art. $2^{\circ}$ do Código Civil brasileiro: a personalidade começa do nascimento com vida, mas a lei protege os direitos do nascituro. Pergunta-se: trata-se, quem vai ainda nascer, já de uma "pessoa" no sentido técnico

1 “[...] a noção fundamental do direito é a de fato jurídico; depois, a de relação jurídica" (PONTES DE MIRANDA, 1954. XVI.) Também assim Mello (2007).

2 Sobre as condições convencionais de uma ontologia convencionalista do social ver Searle (1995). 
do termo? Será talvez uma "quase-pessoa"? Tem "personalidade resolúvel”? Tem "personalidade potencial"? Na "ciência" do direito, discute-se se ao nascituro são reconhecidos propriamente "direitos subjetivos", ou se meras "expectativas de direito" (merecendo tutela excepcional, para a preservação de um possível e provável "direito futuro", ou "eventual"); como se se discutissem estados empíricos e não convenções.

Tais discussões andarão sempre em círculo, porque as convenções serão, em última instância, o que se disser que elas são. "Prova-se", ao final, com esses debates alguma coerência ou incoerência com modelos teóricos. E só. O problema teórico do status do nascituro, na prática, e é o que interessa retoricamente, pode ser refletido doutrinariamente das mais diversas maneiras, mesmo quando a prática se verifique convergente num único e conveniente modus faciendi, que dê ao nascimento com vida um papel decisivo. É sempre possível, afinal, que duas explicações teóricas distintas - e reciprocamente excludentes - possam legitimar uma mesma solução prática para os casos (STAMFORD, 2000).

Em semelhante nível de abstração, discute-se ainda se há direitos "sem sujeito", ou se uma "relação jurídica" se pode dar entre "pessoas" e "coisas" (CASTRO, 1985). Quase nunca se cogita - o que até seria possível sob premissas de uma outra ontologia do direito - de "a relação jurídica" dar-se "entre coisas" puramente. Porém, entre coisas "principais" e "acessórias" há uma relação e não é totalmente verdadeiro dizer que ela não é nalguma medida também "jurídica".

Esses e outros dogmas, como aquele do chamado "sujeito passivo universal" (que, na teoria dos direitos reais, evitará a herética, mas antiga, teoria da relação jurídica entre pessoa e coisa), efetivamente pouco importarão para a prática do regime da propriedade e para a decisão dos casos concretos. O "conteúdo" do direito de propriedade, enfim, em se aceitando a metáfora, não parece se alterar por causa de diferenças estabelecidas em tão abstrato nível de teorização.

Essas discussões metafísicas, que nunca se podem resolver, explicam-se possivelmente por uma necessidade de coerência conceitual, que é uma necessidade retórica. A coerência interna dos modelos teóricos jurídicos é o mais poderoso tópos de sua retórica (SOBOTA, 1990). Para exemplificar essa necessidade de coerência, basta lembrar que processualmente uma sentença "sem lógica", que contrarie a lógica, é uma sentença inválida. Isso pode explicar o investimento tão alto nesses espaços conceituais ao menos imediatamente vazios de prática.

Inutilidade, porém, de modo algum é atributo da teoria do fato jurídico, no seu todo. Se ela não determina a prática, como se crê retoricamente, certamente serve a essa mesma prática. Discussões sobejantes do tipo referido ocorrem sempre de novo, é bem verdade, em relação a certos de seus problemas, mas seu modelo categorial, seu "objetivismo", configura o ambiente todo do falar "jurídico" como ele se desenvolve ainda hoje na tradição romanista. O objetivismo é instrumental para esse falar, senão necessariamente para tomada da decisão mesma, ao menos para a forma retórica de sua apresentação. Os juristas práticos usarão pontualmente a explicação teórica que lhes seja conveniente para legitimar suas decisões, mas a "teoria" lhes restará retoricamente adjutória da oportunidade hermenêutica, do trabalho com os textos legais que se conduzem como "aplicáveis" para os casos.

Certamente, nalguns contextos práticos, a indefinição da teoria de "alta indagação" é inofensiva. O direito, na prática, "funciona" apesar desse tipo de impossibilidade de verificação teórica. Resulta mesmo notável que, não obstante a indiferença prática de semelhantes proposições teóricas, tantas páginas se tenham escrito sobre elas. Que se discute em estratos tão etéreos? As nuvens, como quis Aristófanes, na comédia com esse nome, atacando as especulações de Sócrates; ou o "indizível”, sobre que, a princípio, apenas se deveria calar, como quis Wittgenstein no Tractatus Logicus-Philosophicus (1994)? 
O que parece ocorrer, em tais situações, não é somente alguma forma sofisticada de alienação, ou algum traço "maníaco" presente na doutrina, como uma crítica mais radical talvez possa fazer crer. Esse fenômeno pode, porém, e a par do que a crítica disser, ainda significar uma outra coisa: a manifestação de uma refinada base metafórica, constituindo o espaço imaginário em que se realiza a dinâmica do pensamento jurídico, o "mundo jurídico", a metáfora topológica mirandiana, que interessa neste estudo. É com essa hipótese em retórica que se segue a presente incursão na temática do fato jurídico e se ensaia o anunciado elogio, que é em última instância um elogio estético.

A doutrina realiza seu "ensinar" e "aprender" num ambiente de imagens familiares à comunidade de falantes. Essas imagens não são necessariamente nem verdadeiras, nem falsas. Elas constituem o mundo como ele se dá na interação comunicacional, como ele "aparece", como se "apresenta" discursivamente. As imagens da teoria não são imperativos, comandos ou ordens, embora se possa dizer que têm certo caráter "normativo", como na ideia de "modelos jurídicos". São, porém, sempre também metáforas. Ou melhor, podem e devem ser vistas, ou reconstruídas, como metáforas.

\section{AS METÁFORAS DA TEORIA: TEORIA COMO VISÃO}

Teorias não escapam às metáforas. Mesmo a física, que se pode tomar como paradigma da ciência em sentido literal, vale-se de metáforas. ${ }^{3}$ Theorèin significava originalmente "contemplar", "ver". O theóros, na Grécia antiga, era um espectador de competições esportivas, que via os jogos sem participar.

Em termos meramente extensionais, a visão explica-se como um evento ocorrendo nas células nervosas de um específico aparelho orgânico de alguns seres vivos. O "ver" é um padrão de excitação elétrica de determinados tecidos vivos. Porém, "ver" também é a "vivência" da percepção visual. É agora mais do que o simples padrão elétrico; é a "experiência" sensorial do ver, do perceber pelos olhos. ${ }^{4}$ Falar em "experiência" envolve já a instalação de uma dualidade. Não é mais mera extensão aquilo do que se trata. Para conceber a percepção, é preciso separar um "sujeito" de um "objeto". É preciso "partir" o que restava uno.

O mundo cartesiano, assim concebido, é precipuamente visual. ${ }^{5}$ Ver com os olhos é desde então também perceber com a mente. As percepções visuais passaram a ser, desde esse tempo,

\footnotetext{
3 Hubert Reeves (apud CORDOZ, 1994. p. 13-23, passim), escrevendo sobre "Imagens de Ação na Física”, explica: “A física, como todas as outras ciências, procede por meio de imagens. Descreve a realidade, tentando assimilá-la a um conjunto de imagens." Segundo o astrofísico, antes do fim do Século XIX, "a física era dominada por duas imagens de objeto: a bola e a onda". Elas foram substituídas por "imagens de ação", ou "operações". "O acento não está no “objeto" que se desloca, mas sim no 'fato' de se deslocar". Sua conclusão é a seguinte: "as imagens de ações se desenvolvem 'antes' das imagens de objetos. Bem antes de pensar, a criança age. [...] Essas ações são acompanhadas de um 'esquema de ações'. [...] Vêem-se aparecer aqui as noções de operações equivalentes e de grupos de operações".

4 Como afirma Andrea Bonomi (2001), "nenhuma teoria baseada na distribuição local dos estímulos sobre a retina poderá jamais dar conta do fato de eu 'ver' os objetos que se articulam no campo visual, já que os estímulos contam menos por sua localização anatômica (por exemplo, por sua distribuição 'geométrica' sobre a retina) do que por suas conexões recíprocas na totalidade do processo."

5 Segundo Richard Rorty (1994. p. 55), a tensão estabelecida entre os dois lados do nosso ser, "nossa Essência especular" não era, no século XII, uma doutrina filosófica, mas uma imagem que os homens letrados encontravam pressuposta por cada página que liam. O humano seria "especular" (relativo ao espelho) por duas razões. Primeiro, porque, em relação à imagens que reflete, o espelho assume novas formas sem ser mudar a si mesmo. Segundo, porque "a essência do homem é sutil e delicada como a do espelho". A resistência, no sentido de força para permanecer, dessa concepção é antiga. Segundo o mesmo Rorty (1994, p. 53), "os filósofos com freqüência desejaram que Aristóteles nunca tivesse aceito a conversa de Platão sobre universais e sua teoria do conhecimento do espectador, e que sua
} 
referidas em termos de percepção mental, frequentemente com pouca, se com alguma, consciência da metáfora.

A teoria assim concebida é "visão", "reflexo", ou até "retrato". Todos conhecem a renúncia de Wittgenstein a essa abordagem da linguagem teórica. Talvez importe lembrar apenas o quanto a dogmática jurídica está longe do que Wittgenstein consideraria "dizível”, segundo o Tractatus.

Especificamente, abordam-se neste texto metáforas visuais, porque elas “denunciam” claramente a forma de se organizar o pensamento do jurista ao justificar sua prática.

Pensando em termos de metáforas cognitivas, que derivam de experiências corporais primeiras fundamentais, George Lakoff (1986. p. 16) observa que a experiência corpórea do "ver", consistindo no experimentar e discernir horizontes e limites, inclusões e exclusões, faz com que a associação entre "teorizar" e "ver" se possa manifestar como ocorrência da metáfora dicotômica "continente" / "conteúdo". O campo visual seria o "continente", o que se vê o "conteúdo". Essa seria a metafórica subjacente à apresentação linguística do "conhecer".

Já Aristóteles (1952, I, 1, 980 a) tinha a visão como o sentido humano mais intelectual. Para Lakoff, podem ser apontadas três razões para esse paralelismo metafórico entre visão e intelecção:

1. a visão é nossa fonte de dados primária em relação ao mundo, significando que a visão tipicamente nos fornece mais informação do que qualquer dos outros sentidos, exercendo papel decisivo no acúmulo de conhecimento;

2. a visão envolve a habilidade notável de focalizar arbitrariamente diversos aspectos do campo de percepção;

3. a visão é mais ou menos idêntica para diferentes pessoas, a partir de um mesmo "ponto de vista". ${ }^{\circ}$

Metaforicamente, como se verá adiante, a "regra jurídica" funcionará na doutrina do fato jurídico de Pontes de Miranda, como um "olho", capaz de captar a informação existente no ambiente, i.e. existente fora do "mundo do direito". A regra "incidirá" sobre o evento, como um olhar, "juridicizando-o". A natureza óptica da metáfora da "incidência" parece inquestionável. Essa "incidência", por sua vez, só pode ser captada de novo por um "olho" mental do jurista, que se substitui, no momento da aplicação, ao olho da regra que viu a ocasião de incidir. Sob o manto desta metafórica, que está ao mesmo tempo exposta e encoberta pelo que se diz, capacita-se o jurista a "observar" fatos jurídicos. Eles estão a "entrar" no mundo do direito, "vindo" do mundo dos fatos, como outrora foi visto pelos olhos da regra mesma que incidiu, e tudo isso no momento em que o suporte fático se dá.

\section{O PARADIGMA "OBJETIVISTA" E O ÂNIMO DOGMÁTICO DE CLAS- SIFICAR CONCEITOS}

Seja permitido desdobrar a questão do "ponto de vista" neutro e objetivo. Platão (1952, X, 596 d), distinguindo a coisa de sua respectiva percepção, notava que uma cama, por todo novo

Entwicklung tivesse durado o suficiente para que passagens como De Anima III, 5 e Metafísica XII fossem expungidas como juvenalia."

6 Cf. Bonomi (2001, p. 108) e também Hacking (1975, p. 108). 
ângulo que fosse vista, aparecia ao observador sempre de maneira diversa, em perspectiva, mas continuava ela própria ainda a mesma e indiferente cama.

Hoje em dia, o linguista George Lakoff, diante da tradição ontológica que por intermédio de Platão se desenvolveu, observa viger no Ocidente o que chama de um "paradigma objetivista". Por tal modo de conceber a relação entre o pensamento e as coisas, as "categorias" designariam os gêneros mais abstratos do dizer e seriam metaforicamente concebidas como espécies de "recipientes" (de acordo com uma metafórica da oposição "continente"/“conteúdo"): as coisas todas ou bem estão nas categorias inseridas ou o inverso, bem estão delas excluídas (distribuição categorial). Objetos são referidos por uma mesma categoria se e somente se partilham um quid comum. ${ }^{7}$

O esquema de categorização baseado em "gêneros próximos" e "diferenças específicas" finca suas raízes na diérese platônica, no processo de "divisão" ou "partição" dos conceitos em função de se lhes afirmar ou negar um atributo absoluto. ${ }^{8}$ Esse esquema platônico é retomado nas Categorias de Aristóteles. Assim é que, a partir da categoria "substância", distingue o Estagirita, repartindo as coisas, uma substância que é "corpórea" de outra que não o é; depois, dentre as corpóreas, separa a substância que é "animal" da que não; depois, dentre os animais, divide os que são "racionais" dos que não etc. até alcançar o individual concreto. Os comentários que Porfírio, no Séc. IV, teceu sobre as Categorias de Aristóteles (na verdade a introdução que para o texto aristotélico preparou, a Isagoge) tiveram forte influência durante toda a Idade Média, a ponto desse esquema de ramificação invertida (dividindo-se as ramas de cima para baixo) ser notoriamente conhecido como a "Árvore de Porfírio". . Ele faz-se presente em muitas ilustrações didáticas da época.

A árvore categorial, a Árvore de Porfírio, representa um esforço de classificação e objetivação da ordem do mundo. Esse esforço é decisivo para a história do pensamento Ocidental e parece estar presente na metodologia numa enorme maioria dos empreendimentos a que costumamos chamar de "ciências". A biologia é o exemplo mais evidente. Todo o problema taxonômico que houve diante da descoberta do ornitorrinco é exemplo disso, cujas conseqüências teóricas o próprio Eco explora.

A doutrina do fato jurídico tem uma índole classificatória semelhante. Como antes já se disse em relação à lingüística estruturalista, atitudes de ênfase classificatória como a da teoria do fato jurídico se poderiam conceber como uma "botânica taxonômica" do jurídico. Porém o que ela classifica são seus próprios conceitos, como se eles estivessem denotativamente conectados a estados de coisas no mundo.

Por um lado, construir semelhantes sistemas será a tarefa por excelência de lógicos do direito, por outro, esses sistemas, extrapolando o meramente "lógico", têm o papel de metáforas que dão ambiente retórico e aparência de "objetividade" para o discurso jurídico, caso em que se situa a "teoria do fato jurídico" aqui explorada. É dessa última hipótese que se vai ocupar aqui. Nesse sentido, que é o sentido da obra de Pontes de Miranda, a dogmática jurídica se apresenta

7 Assim, diz George Lakoff (1986, p. 6) que desde o tempo de Aristóteles até o trabalho último de Wittgenstein as categorias foram compreendidas como containers. Esse modo de estruturar a teoria das categorias, como adiante será referido, está em Lakoff ligado a projeções metafóricas tomadas da experiência do "ver".

8 Cf. Kneale e Kneale (1980, p. 22).

9 Cf. Eco (1998, p. 28). 
ela mesma como uma "lógica". Não como uma reconstrução lógica, mas como intrinsecamente uma lógica. ${ }^{10}$

As proposições desse sistema lógico seriam as das regras de direito mesmas. Nos modelos lógicos propriamente ditos, o que pretende é uma "reconstrução" deliberada, noutro sistema artificial, do jogo de linguagem que se dá na linguagem natural. ${ }^{11}$ Em Pontes de Miranda, porém, não é isso o que ocorre. É o próprio direito positivo que é uma lógica. Essa perspectiva retoricamente é mais simples e mais funcional, conquanto seja a mais difícil de se sustentar epistemologicamente, porque requereria abstrair totalmente as questões da interpretação dos textos com que se exprimem as regras de direito.

\title{
5. CiênCia do direito em Pontes de Miranda
}

Pontes de Miranda, jurista e também matemático, explorou à sua maneira a correlação entre a idealidade do direito e a idealidade da lógica e da matemática. Dizer, como ele diz, que o direito é um sistema lógico tem uma significação toda especial para a presente investigação.

Rejeitando a ideia de que os mecanismos formais do raciocínio jurídico se realizam "por uma lógica imperfeita" (por uma lógica deôntica, que cuida não do que "é", mas do que "apenas" deve ser), propunha Pontes de Miranda que o sistema das regras de Direito fosse representado como um mundo ideal perfeito, tão perfeito quanto perfeita se pudesse manter a distinção entre o que se passa no "mundo dos fatos" e o que se passa "no mundo do direito".

Pontes de Miranda (1954, p. 37-38) construiu a seguinte metáfora, emblemática de sua "visão" do fenômeno jurídico e da maneira como abstração e realidade para ele se unem:

\begin{abstract}
Quem está dentro de sistema jurídico, qualquer que seja a sua extensão espacial, é como quem se move em grandes jardins, cheios de curvas e retas, saliências e anfractuosidades. Ali estão as incidências: o pensamento do planejador do jardim caiu sobre o terreno e criou aquelas arrumações, aqueles efeitos, realidades novas para o estado anterior, de matagal ou de terra desnuda. Seja como for, nem todos os movimentos que se podiam fazer por ali seriam, hoje, possíveis sem se pisar no jardim. Pisar no jardim não é apagar as incidências. É apenas machucar o gramado, danificar as plantas, deixar marcas fundas nos canteiros. Noutros termos: ferir as realidades não as incidências; o plano de jardinação continua a existir, e a intervenção do Estado para reparar o jardim não é diferente da ação dele, através da justiça e da própria administração, para reparar o que se destruiu às realidades criadas pelas incidências jurídicas.
\end{abstract}

Para Pontes de Miranda (1954, p. 8), "pelo trato teórico e prático, as regras jurídicas são objeto de pensamento e momentos de vida". Nessa metáfora evidencia-se o modo como se mesclam na concepção mirandiana o "real" e o "ideal", bem como o modo como a participação humana intervém nessa dinâmica.

É interessante notar essa idéia de que o pensamento "cai”. E nessa queda confirma-se tanto a oposição, quanto a união entre pensamento e realidade. Essa "queda", aqui seria uma metáfora da "incidência". Interessa observar: Pontes cria um metáfora para encobrir outra, fazendo assim essa última parecer uma literalidade, um conceito denotativo científico, técnico apenas.

\footnotetext{
10 "Esta instância metodológica identifica o significado do termo com o conceito referencial, o que conduz ao estabelecimento de um conteúdo exato para a lei. O conceito seria, então, uma categoria conceitual estável, indiscutível, com significação fechada. A dogmática jurídica se identifica então com a lógica jurídica.” (WARAT, 1995. p. 17).

11 Ver por exemplo Alchourron e Bulygin (2002).
} 
A primeira coisa que um jurista tem que "ver" na metafórica mirandiana é uma topologia de mundos. Há mundos que se contém e mundos que são contidos. $\mathrm{O}$ "mundo do direito" e o "mundo dos fatos", este que compreende aquele. Por isso, enquanto o direito é específico processo de adaptação social no mundo dos fatos, "os sistemas jurídicos são sistemas lógicos, compostos de proposições que se referem a situações da vida, criadas pelos interesses os mais diversos. Essas proposições, regras jurídicas, prevêem (ou vêem) que tais situações ocorrem, e incidem sobre elas, como se as marcassem." O sistema jurídico abriga regras jurídicas, e essas, por sua vez, "se formulam com os conceitos jurídicos" (PONTES DE MIRANDA, 1954, XVI).

Sem embargo da metafórica explícita de seus textos, poucos juristas brasileiros estiveram tão perto da "ciência em sentido literal" quanto o alagoano Francisco Cavalcanti Pontes de Miranda. Seu "Sistema", por exemplo, inicia com o problema da relação entre número e realidade. A postura do cientista diante do mundo consiste no seguinte: "o que a ciência afirma e o que é fecundo para ela é a concepção de que, no mundo, tudo é teoricamente mensurável" (PONTES DE MIRANDA, 1972a. p. 10). Suas reflexões assentam-se num monismo metodológico no qual o mundo físico, o biológico e o mental remetem a uma mesma ordem de coisas.

A tendência do naturalismo empirista como o de Pontes é a de anular a diferença entre sujeito e objeto, instaurando, ao arrepio da fenomenologia, um monismo no qual a única realidade é a "natureza". Seguindo essa trilha, Pontes de Miranda desenvolve a teoria dos "jetos", colocando "entre parênteses" - num sentido distinto, mas análogo ao de Husserl - os prefixos "sub-" e "ob-" 12 .

No contexto desse naturalismo monista e empirista, para (PONTES DE MIRANDA, 1972a, p. 104):

[...] o princípio da liberdade e a causalidade são as duas feições, uma espiritual e outra material, do mesmo fenômeno, uma subjetiva e outra objetiva: nenhuma é oposta à outra na realidade, isto é - não se contradizem no presente, nem no passado, quer dizer: no que é e no que foi. A contradição surge no futuro, no que vai ser.

Toda especulação deve manter-se no nível do controlável empiricamente. "O direito deve viver de realidade, e não de abstrações” (PONTES DE MIRANDA, 1972a, p.68). Uma das teses centrais de seu pensamento consiste em afirmar que "é o Homem mais que simples conceito: é realidade viva, organismo cientificamente observável” (PONTES DE MIRANDA, 1972a, p. 15). O conceito de fato social e de adaptação social são centrais na teoria mirandiana.

Para Pontes, o direito, como a moral, a religião, a arte, a política, entre outros, são "processos de adaptação social"13. Portanto, em Pontes de Miranda "adaptação social" não é simplesmente uma metáfora darwinista. A adaptação social que constitui o direito dá-se dentro do que Pontes chama de "relação jurídica", um conceito nitidamente haurido da tradição pandectística. Ferraz Jr. (1988, p. 98) explica que "sendo todas as relações de direito, de um lado direitos (subjetivos), de outro obrigações, a adaptação resulta de que cada parte consegue seus fins dentro da relação jurídica, por mais curto caminho e tempo, com menor perda de energia e menor esforço do que fora da relação jurídica".

Para Pontes de Miranda, "o direito" já existiria enquanto tal, antes mesmo do momento da sua "aplicação". O direito aperfeiçoar-se-ia como realidade ideal na "incidência" da norma,

12 "Chamamos jeto a tudo que se apresenta, seja de ordem estritamente física, seja de ordem psíquica, desde que considerado sem ser do lado de quem vê ou do outro lado, isto é, eliminados os elementos que representem oposição entre eles, operação que exprimimos pelo "por entre parênteses os prefixos de (su)jeito e de (ob)jeto". (PONTES DE MIRANDA, 1972b. p. 97)

${ }^{13}$ Conforme expõe Ferraz Jr. (1988, p. 96), o projeto de ciência do direito de Pontes de Miranda pressupõe, entre outros aspectos, uma concepção do social "quase inorgânica, não antropomórfica nem biomórfica". 
que terá ou não ocorrido, não na sua "aplicação", que apenas deverá ou poderá haver; que se dará, ou não. As regras e o sistema jurídico existiriam nesse modelo como existem os sistemas lógicos, numa esfera de realidade ideal própria, mas não menos verdadeira e real que o mundo dos fatos.

Apesar de toda essa base filosófica e sociológica, a teoria do fato jurídico em Pontes de Miranda remete, muito especificamente, a uma literatura mais estritamente civilística, sendo essa uma característica forte sua.

\section{6. "MUNDO DO DIREITO” E "MUNDO DOS FATOS” E METÁFORAS ES- PAÇO-TEMPORAIS}

No Século XIX, Savigny (1981, p. 13) já definira "fato jurídico" como o evento em virtude do qual as relações jurídicas "nascem e extinguem-se". ${ }^{14}$ Observe-se como essa definição de Savigny polariza "eventos" de um lado e "relações jurídicas" de outro. Segundo essa imagem, algo ocorre na dimensão material dos eventos e esse algo afeta as relações jurídicas. As "relações jurídicas", estas somente nascem, modificam-se ou extinguem-se em virtude dos "fatos jurídicos". Os fatos são causa, as relações, efeitos. A regra jurídica é que estrutura e realiza essa interação do "fático" com o "jurídico". Entender o fenômeno jurídico, por essa perspectiva, equivale a poder representá-lo adequadamente em termos de "causas" e "efeitos". Para fazê-lo, a teoria do fato jurídico pressupõe a divisão do mundo em (pelo menos) dois. Se há o fato "jurídico", há também o fato puro, "não-jurídico".

A terminologia de Pontes de Miranda é: de um lado, o "mundo dos fatos"; de outro, o "mundo do direito". O "mundo do direito" é o mundo ideal onde se têm as "regras de direito", as "relações jurídicas" e os "fatos jurídicos". Relações jurídicas "existem" no mundo do direito. "Movem-se" em "planos", da "existência", "validade" e "eficácia". Toda transformação que o "mundo do direito" experimenta decorre da reação no mundo do direito a um evento passado no mundo dos fatos, que é como que "lido" pelo "olho" da regra.

Primeiro, há de acontecer um evento. Esse evento, num primeiro momento, supõe-se "puro", pré-jurídico. Nessa dimensão primeira, ainda não se fala de "fato jurídico". Não há ainda qualquer adjetivação para o evento, a que, nesse nível, Pontes de Miranda denomina de "suporte fático", que é sua tradução para a expressão alemã Tatbestand. ${ }^{15}$ No entanto, é preciso considerar que para que o "suporte fático" já se entenda como sendo "um" certo e determinado "algo", apreensível ou verificável de algum modo, pressupõe-se que ele tenha alguma unidade, o que somente seria possível, e já se está de novo andando em círculos, a partir da perspectiva de uma "forma", o que conduz ao paradoxo da origem da normatividade, que Kelsen não resolve, mas confirma com a sua teoria da "norma fundamental". ${ }^{16}$

"Suporte fático" é uma expressão que busca representar o evento que será convertido em fato jurídico, antes que essa conversão se tenha operado. Está situado como potencialidade jurídica. Se o evento acontecido vier a corresponder à descrição hipotética, inscrita numa regra do

\footnotetext{
14 “A definição de Savigny, naturalmente, sofreu a crítica da doutrina pela razão de se haver limitado a referir o nascimento e a extinção das relações jurídicas, sem mencionar as transformações porque elas passam e outros efeitos que se verificam, também, em virtude dos fatos jurídicos." (MELLO, 2007, p. 109)

15 Para Pontes de Miranda (1954, p. 19): “o suporte fáctico (Tatbestand) da regra jurídica é aquele fato ou conjunto de fatos que o compõe, e sobre o qual a regra jurídica incide.”. Cf. também Adeodato (2002, p. 243).

${ }^{16}$ Cf Kelsen (1992, p. 30 e ss.).
} 
sistema jurídico, então essa correspondência é a circunstância que basta para que se possa falar de "incidência" dessa norma sobre esse "suporte fático".

A incidência da norma sobre o fato, ou melhor, sobre o suporte fático dado, "colore-o", no dizer de Pontes de Miranda (1954, p. 13). Antes de ocorrer a incidência, por isso, não há cogitar de "fato jurídico". O fato só é "jurídico" quando já se tem por pressuposta essa correspondência com a "previsão" contida numa norma jurídica, que está pressuposta pela ideia de "incidência". Quer dizer, a norma só incidiu porque houve correspondência do suporte com a hipótese da regra e essa correspondência a regra reconhece, vê.

Quando se diz "fato jurídico", fala-se, portanto, de algo que não é mais o "evento" em si. O "suporte fático", agora "colorido" pela incidência, projeta-se dentro do "mundo do direito". $\mathrm{O}$ "fato jurídico" é uma outra coisa, distinta do fato real-material que o antecede logicamente e o consubstancia no "mundo dos fatos". É um retrato que a regra "representa".

O conceito de incidência contrapõe-se, na semântica jurídica, ao de aplicação. Em Pontes de Miranda, a incidência é anterior à aplicação, que se pode dar ou não. Mas isso cria um problema. A incidência da regra de direito, segundo Pontes de Miranda (1954, p. 16) caracteriza-se pela "infalibilidade" e pela "inesgotabilidade". Ser a incidência infalível significa dizer que ela é idealmente perfeita independentemente da aplicação. Ser inesgotável também reforça essa natureza ideal: toda vez que o suporte fático se realiza, a norma instantaneamente "incide".

Observa-se que a incidência da norma não se pode dar independentemente da participação humana. Isso, que é evidente, evidentemente não é olvidado na teoria mirandiana, mas simplesmente ocultado. Desnecessário dizer. Assim, dizer que a norma incide é dizer que alguém pensa essa incidência como tendo ocorrido de tal e tal forma em tal e tal data e, por isso, por ser pensada assim, ela ocorreu de forma tal e tal em tal e tal data. ${ }^{17}$

Desta forma, entre a "incidência" e a "aplicação" da regra é possível imaginar um interregno útil como distinção da dogmática. Segundo Pontes de Miranda (1954, p. 30), "regra jurídica e suporte fático hão de [co]existir no momento em que se dê a incidência. Não é preciso que [isso] ocorra no momento da aplicação" (colchetes incluídos agora). Isso oferece uma metafórica de espaço-tempo, que servirá para situar formalmente questões relativas à "retroação" dos "efeitos" da lei.

Em outras palavras, a diferença está no fato de que, em Pontes de Miranda, o "revestimento" de juridicidade que a regra de direito empresta ao fato pela incidência decorre instantaneamente, e como se independesse da intervenção humana, da coexistência num determinado tempo. Assim ele encobre toda a problemática da interpretação dos fatos e das regras.

Do ponto de vista pragmático, a coexistência entre regra e suporte fático depende do agente, sendo irreal pensar na coisa como um mecanismo automático: a norma incide, em lugar dos homens fazerem-na incidir. Para Pontes de Miranda (1954, p. 61), porém, "a regra jurídica dispositiva incide, ainda se o interessado ou os interessados desconheciam a lei, ou não a interpretaram bem, ou julgaram ser de incidir uma regra jurídica, em vez de outra.”

E no que há de encoberto na discussão sobre a dicotomia "incidência" versus "aplicação" pode ser recontado em termos de metáforas temporais. Repare-se que em ambos os casos o apelo é no sentido de um tempo perfeitamente "objetivo". Pontes de Miranda afirma que todo evento tem data e lugar. E que é na sua data e no seu lugar que surge o "fato jurídico", pela "incidência"

\footnotetext{
${ }^{17}$ Segundo Paulo de Barros Carvalho (1999, p. 09): “[...] é importante dizer que não se dará a incidência se não houver um ser humano fazendo a subsunção e promovendo a implicação que o preceito normativo determina."
} 
da norma. Barros Carvalho igualmente reconhece a objetividade do tempo, mas somente para usá-la em seu favor, já que considera irreal a incidência automática.

Stephan Kirste concebe duas maneiras de conceber a questão do tempo. Uma primeira refere a um tempo objetivo externo ao direito e que o abarca. Outra refere a um tempo subjetivo, variável segundo a percepção de quem o considera. ${ }^{18}$ Olhando desde uma distinção desse tipo, pode-se reconstruir cada um dos dois modelos como representando diferentes metáforas temporais a partir dessas duas possibilidades.

No modelo de Pontes, a linha de tempo corre "positivamente" desde o evento até a aplicação.

No modelo de Barros Carvalho, que é também o modelo de Kelsen, que abole toda eficácia ex tunc, a linha do tempo só corre "negativamente", ou seja, somente "terá corrido", como uma abstração que regressa, pela construção do lingüística do "fato", a retomar ficcionalmente o tempo do "evento". Mas é pragmaticamente o agente decisor, criando linguagem e norma, que se faz projetar no tempo.

Ambos os modelos, como se vê, são igualmente metafóricos em relação à continuidade do tempo, apesar de ambos preocuparem-se tão enfaticamente com a "objetividade" de suas considerações.

Tais modelos não se podem tomar como ontologias à vera, como ademais nenhum modelo da dogmática jurídica. São e serão sempre ontologias als $o b$.

\section{CONCLUSÃo}

Haverá um ressaibo cientificista a exigência de um mínimo de "fantasia metodológica"? Não necessariamente; porém possivelmente. Em todo caso, se houver de se conceder lugar a uma "ciência" distinta, no sentido da novidade de Bruno e Galileu, e "limites" para o científico (ainda que limites retóricos), então a minimização das fantasias metodológicas, para os juristas, deles exigirá o reconhecimento da dogmática jurídica ao de lá, do lado de fora desses limites. Teorias como a do fato jurídico não são teorias propriamente "científicas" em sentido literal, mas metafórico (SOUTO, 1974). Não produzem hipóteses teoréticas gerais, que se possam verificar ou refutar controladamente, como a física, química ou biologia, entre outras "insuficiências". ${ }^{19}$

A questão, porém, não será a de se investigar se "direito" é "ciência", ou não; isso realmente não pode ser levado a sério assim, em termos tão vagos; afinal, será ciência aquilo a que se estipular como sendo ciência. Não haverá de ser impossível que "o direito" seja, ou que fosse, ou que venha a ser, portanto, uma "ciência". Importa aqui, indiferentemente, observar que há

${ }^{18}$ A questão, como a formula Kirste (1998. p. 15), é: "Steht das Recht nur einfach in einer natürlichen Zeit oder gibt es eine eigene Zeitlichkeit des Rechts? Existiert das Recht nur in der geschichtlichen Zeit des Subjekts oder Daseins, oder hat es ihm gegenüber eine eigene Zeitstruktur?".

19 “Os dogmáticos afirmam que sua atividade é científica porque está baseada em raciocínios lógico-demonstrativos. Epistemologicamente isto é inaceitável, pois o discurso jurídico é persuasivo e não demonstrativo. O pensamento dogmático se baseia na identificação da significação verbalmente veiculada com o conceito referencial, o que leva a conceber a possibilidade de um raciocínio silogístico com os enunciados jurídicos. Se, ao contrário, partimos da premissa ou pressuposto metodológico que a significação é constituída no ato de conhecimento pelo sentido comum teórico, fica óbvio que se integra não apenas com o âmbito conceitual e referencial, como também com o âmbito ideológico se, sob a concepção de ideologia incluímos os demais efeitos cognoscitivos e significativos do sentido comum teórico". (WARAT, 1995, p. 37). 
uma retórica da "cientificidade do direito" em jogo, há um papel para esse discurso, que eventualmente, pode até ser um papel "enviesado" em relação ao que ostensivamente se discute.

Vista desde certo ângulo retórico, a esquematização categorial da teoria tradicional do direito, mormente da doutrina do fato jurídico, resulta num expediente de ocultação de relações subjacentes e apresentação de figuras substitutivas, com eminente caráter persuasivo, tudo composto retoricamente como conteúdo cognitivo. O que os juristas tradicionais chamam "regra", chama-se, desde esta perspectiva retórica, "persuasão" e se alguém reclamar que com isso se esvai o próprio conceito de direito, tem razão na reclamação. Sem um argumento “objetivo", não haverá "direito", só poder nu.

A "objetividade" da dogmática jurídica, metodologicamente decorre da contínua redefinição semântica de suas categorias, instanciando suas próprias verdades e efetivando-as com fins decisionais, numa "tecnologia" (FERRAZ JR, 1998) de neutralização das decisões tomadas em função da forma de sua apresentação. Essa estratégia de discurso, epistemologicamente, do nível de uma imposição semântica e de sintaxe não passa. Entretanto, a proposta de um encômio à "objetividade" do jurista se justifica por uma questão de preservação da própria disciplina, de preservação da "retórica jurídica". Não se trata de materialmente pleitear legitimidade epistemológica para tal doutrina, mas de entender sob que condições ela pode retoricamente ser sustentada como discurso "objetivo", mesmo que não "científico", como parece necessário pelas razões acima referidas de que sem "objetividade" o direito perde sua qualidade retórica mais elementar. Sem esse adjetivo (o "jurídico") tomar uma forma substantiva, o próprio valor da disciplina em questão, numa escola de direito, parece se esvair.

A teoria do fato jurídico reforça a objetividade do direito de uma maneira própria, da qual Pontes de Miranda soube tirar máximo proveito. Seu sistema apoia-se na referencialidade do fato jurídico, cuja incidência concebe determinada no tempo e no espaço. Isso cria uma circunstância única, um advento também lógico cujas consequências sintático-semânticas sempre se podem calcular. Isso contextualiza uma acepção de "direito subjetivo" também determinada, i.e. especificada pelo fato jurídico e pela incidência espaço-temporalmente situada, a qual contrasta com outra acepção mais indeterminada, que ocorre no uso da expressão "direito fundamentais", que acompanham a pessoa por toda sua existência. Para essa última a questão de sua determinação espaço-temporal não tem tanta importância.

A propósito da maior especificidade ou concreção dessa linguagem, que assume a demarcação, classificação e determinação da incidência espaço-temporal como tarefa central do ofício jurídico, uma tarefa de cientistas, portanto, observe-se o quanto esse expediente oferece sofisticação analítica (e retórica) ao discurso do direito.

A teoria do fato jurídico constitui a linguagem metafórica com que se realiza uma prática decisional dos juristas, que lhes é como queria Pontes de Miranda, adaptativa e econômica. Assim, quando se a invalida epistemologicamente, abala-se a base persuasiva mais tradicional do direito, a objetividade de seu discurso.

A todo custo retórico essa objetividade busca manter-se na teoria do direito, pretendendose, como no positivismo, que esta deva cuidar de uma "descrição" do direito posto. A possibilidade de descrever semelhante objeto, que mal é "objeto", é bastante precária epistemologicamente. Porém, não é de todo inexistente a possibilidade de uma tal descrição. Tudo depende do grau de determinação a que se pretenda chegar. Todo mundo é capaz de relatar: "seu rei mandou dizer que..." Ser isso uma ciência é que é outra questão. Por um critério assim, somente por ser possível alguma descrição, toda metalinguagem por si mesma seria "científica". Num sentido epistemológico estrito, porém, nem mesmo semiótica, nem tampouco semiologia se podem dizer 
ciências, porque seu objeto, "o significado", é radicalmente indomesticável em sua intencionalidade.

Qual o preço do afastamento do relativismo retórico que se exige para o elogio de uma metodologia assim configurada? Trata-se de uma ruptura com o ambiente antifundacionista que se acomoda entre, de um lado, pós-estruturalismo, de outro lado, pragmatismo, ainda de outro, hermenêutica filosófica? Ou seja, seria uma ruptura com os pressupostos daquilo que se chamou genericamente de "virada linguística" da filosofia contemporânea? (RORTY, 1990. p. 45 e ss.) Sim e não.

O que parece é que a forma adjetivada "retórica jurídica", como nome para essa disciplina de faculdades de direito, carrega-a de um peso inusitado em comparação a outras perspectivas que se pretendam tão-somente "retóricas". Numa certa medida, toda retórica só se torna "jurídica" se ela passa a advogar pelo "Direito", com "D" maiúsculo, como que postulando por uma "objetividade" única, com características quase divinas; tomando seu partido "teológico", digamos assim. ${ }^{20}$

O jurista parte da condição "objetiva” de sua ocupação; essa é sua condição retórica, aquela que ele não pode contornar (SOBOTA, 1990).

Isso não autoriza negar o saber teológico como saber. Seu valor é um valor prático, está na ordem que impõe ao mundo, na demarcação de seu próprio jogo, sua própria categorização. Como Pontes de Miranda dizia, é mais econômico assim. Por outro lado, essa mesma "sabença", como objeto de estudo histórico, precisa ser retomada e repensada, sempre de novo, ser, portanto, reconstruída retoricamente, e a melhor forma de se fazê-lo parece ser retomando-se a sua metafórica. Tem-se assim relativização, sem perda do sentido constitutivo daquela linguagem.

\section{REFERÊNCIAS}

ADEODATO, João Maurício. Ética e retórica: para uma teoria da dogmática jurídica. São Paulo: Saraiva, 2002.

ALCHOURRON, Carlos E.; BULYGIN, Eugenio. Introducción a la metodolgía de las ciencias jurídicas y sociales, $4^{\mathrm{a}}$. Reimpresión. Buenos Aires: Astrea, 2002.

ARISTÓTELES. Metaphysics. Trad. W. D. Ross. Chicago/London/Toronto: Encyclopaedia Britannica, 1952.

BONOMI, Andrea. Fenomenologia e estruturalismo. São Paulo: Perspectiva, 2001.

CANARIS, Claus-Wilhelm. Pensamento sistemático e conceito de sistema na ciência do direito. Lisboa: Calouste Gulbenkian, 1989.

CASTRO, Torquato. Teoria da situação jurídica em direito privado nacional. São Paulo: Saraiva, 1985.

CONFERÊNCIAS do III Congresso Brasileiro de Filosofia Juridica e Social, Instituto Brasileiro de Filosofia em Homenagem a Pontes de Miranda, São Paulo, 1988.

${ }^{20}$ Segundo Schmitt (2006, p. 33): “Todos os conceitos concisos da teoria do Estado moderna são conceitos teológicos secularizados. Não somente de acordo com seu desenvolvimento histórico, porque ele foi transferido da teologia para a teoria do Estado, à medida que o Deus onipotente tornou-se o legislador onipotente, mas, também, na sua estrutura sistemática, cujo conhecimento é necessário para uma análise sociológica desses conceitos.” 
CORDOZ, André et al. A ciência e o imaginário. Trad. Ivo Martinazzo. UnB, Brasília, 1994. ECO, Umberto. Kant e o ornitorrinco. Trad. Ana Thereza B. Vieira. Rio de Janeiro: Record, 1998.

FERRAZ JR, Tercio Sampaio. Função social da dogmática jurídica. São Paulo: Max Limonad, 1998.

GAST, Wolfgang. Juristische Rhetorik. 4. Auflage, Heidelberg: C. F. Müller, 2006.

HACKING, Ian. Why does language matter to philosophy. Cambridge: University Press, 1975.

JHERING, Rudolph von. Bromas y veras en la jurisprudencia: un regalo de Navidad para los lectores de obras juridicas. Trad. Tomás A. Banzhaf. Buenos Aires: EJEA, 1974.

KELSEN, Hans. Reine Rechtslehre. 2. ed. Wein: Österreichische Staatsdruckerei, 1992.

KIRSTE, Stephan. Die Zeitlichkeit des positiven Rechts und Geschichtlichkeit des Rechtbewusstseins: Momente der Ideengeschichte und Grundzüge einer systematischen Begründung. Berlin: Duncker und Humblot, 1998.

KNEALE, William; KNEALE, Martha. O desenvolvimento da lógica. Trad. M. S. Lourenço, 2. ed. Lisboa: Calouste Gulbenkian, 1980.

LAKOFF, George. Women, fire and dangerous things: what categories reveal about the mind. Chicago/London: The University of Chicago Press. 1986.

MELLO, Marcos Bernardes de. Teoria do fato jurídico (plano da existência). 13. ed. São Paulo: Saraiva, 2007.

PLATÃO. Dialogues. trad. Benjamim Jowett. Chicago/London/Toronto: Encyclopaedia Britannica, 1952.

PONTES DE MIRANDA, Francisco Cavalcanti. O problema fundamental do conhecimento. 2. ed. Rio de Janeiro: Borsoi, 1972b.

PONTES DE MIRANDA, Francisco Cavalcanti. Sistema de ciência positiva do direito. 2. edição. Rio de Janeiro: Borsoi, 1972a.

PONTES DE MIRANDA, Francisco Cavalcanti. Tratado de direito privado. Tomo 1. Rio de Janeiro: Borsoi, 1954.

RORTY, Richard. A filosofia e o espelho da natureza, trad. Antônio Trânsito. Rio de Janeiro: Relume-Dumará, 1994.

RORTY, Richard. El giro lingüístico. Trad. Gabriel Bello. Barcelona: Paidós Ibérica, 1990.

SCHMITT, Carl. Teologia política. Trad. Elisete Antoniuk, Belo Horizonte: Del Rey, 2006.

SEARLE, John. The construction of social reality. London: Penguin, 1995.

SOBOTA, Katharina. Sachlichkeit rhetorische Kunst der Juristen. Frankfurt am Main: Peter Lang Verlag, 1990.

SOUTO, Cláudio. Teoria sociológica geral. Porto Alegre: Globo, 1974.

STAMFORD, Artur. Decisão judicial: dogmatismo e empirismo. Curitiba: Juruá, 2000.

WARAT, Luiz Alberto. Introdução geral ao direito. Tomo II. Porto Alegre: Sérgio Fabris, 1995. 
WIEACKER, Franz. Historia del derecho privado de la edad moderna. Trad. Francisco Fernández Jardón, Aguilar, Madrid, 1957.

WITTGENSTEIN, Ludwig. Tractatus logico-philosophicus. Trad. Luiz Henrique Lopes dos Santos (edição bilíngüe). São Paulo: Edusp, 1994.

Recebido em: 2 jan. 2018.

Aceito em: 29 mar. 2019. 